\title{
Synthesis of Bio-gas Using Squander Cooking Oil
}

\author{
Bahig JM${ }^{1 *}$, Mansour $\mathrm{SA}^{2}$, Mohamed $\mathrm{EA}^{3}$, Abd-Elaal $\mathrm{AA}^{3}$, Negm $\mathrm{NA}^{3}$ and \\ Ismail $\mathrm{A}^{4}$ \\ ${ }^{1}$ CO-OP Petroleum Company, Egypt \\ ${ }^{2}$ Misr Petroleum Company, Research Center, Egypt \\ ${ }^{3}$ Egyptian Petroleum Research Institute, Egypt \\ ${ }^{4}$ Environmental Sciences Department, Faculty of Science, Port Said University, Egypt
}

\section{Research Article}

Volume 5 Issue 3

Received Date: July 28, 2021

Published Date: August 30, 2021

DOI: $10.23880 /$ ppej-16000270

*Corresponding author: John Mikhail Bahig, CO-OP Petroleum Company, Cairo, Egypt, Tel: +201005107655; Email: srjejo@ yahoo.com

\section{Abstract}

The point of this examination is to evaluate the performance of both catalytic and thermal cracking processes in the thermochemical conversion of squander cooking oil into biofuel and investigate the impact of ZSM-5 impetus and breaking reactor temperature to items yield, biofuel caloric substance and synthetic arrangement. Several parameters might affect process performance which resulted in different product's yield and specification. Cracking temperature variation gave appreciable effect on yield and product's caloric values.

Keywords: Gas; Cooking oil; Catalyst; Biofuel

\section{Introduction}

These days, worldwide requirement for sustainable power is developing bigger and a serious concern has been centered on its manageability angles like natural effect, and public's financial development thought. Ecological issues emerging from the extreme dependence on energy from petroleum derivatives have supported examination on fuel creation motors utilizing elective fuel sources [1]. There are bounty normal assets which considered as imminent crude materials for biofuel creation [2]. Among these, fatty substance based mixtures, for example, palm oil, fat, and others vegetable oil may become essential elective assets for supporting bio-energy creation [3].

Unrefined vegetable oils are the most critical as far as worldwide creation [4]. Palm oil ware in Indonesia today has gotten quite possibly the most imminent items on the planet. As indicated by Indonesia Ministry of Agriculture report, palm oil interest of Indonesia was more than 2 million tons in 2015. Also, the yearly palm oil creation from Indonesia is roughly 32 million tons and from 8 years' time frame, the general palm oil creation will in general build due to the greater levels of popularity [5]. Furthermore, thusly it will bring about more waste cooking oil particularly from family and mechanical and it offers a chance to treat its squanders fittingly. Squander oil has numerous removal issues like water and soil contamination, human wellbeing concern and aggravation to the amphibian environment [6]. Thus, as opposed to arranging it and hurting the climate, it very well may be utilized as a successful and cost proficient feedstock for biofuel creation as it is promptly accessible and not make contest with different clients or unfavorably affect the food supply chain [3].

There are a few different ways that have been utilized to change over vegetable oil into biofuel, for instance the transesterification response which produce biodiesel [3]. Notwithstanding, utilizing bad quality cooking oil requires extra treatment because of its high free unsaturated fats 


\section{Petroleum \& Petrochemical Engineering Journal}

and rancidity which can prompt low quality of biodiesel [7]. The free unsaturated fats (RCOOH) respond with the antacid impetus and structure cleanser, because of what piece of the impetus is killed and is at this point not accessible for transesterification. The presence of cleanser might meddle with resulting preparing steps. Hence, the FFA content ought to be more modest than $0.5 \mathrm{wt} \%$ and pretreatment like "degumming" measure is some of the time fundamental for FFA evacuation [8]. In this manner, it is important to track down an elective method to change over squander cooking oils into biofuel straightforwardly and it tends to be led by means of breaking measure. The misuse of cooking oil is appropriate as biofuel feedstock to breaking measure since it is made out of unsaturated fats, for example, 10-octadecenoic corrosive and hexadecanoic corrosive. This carbon chains can be broken into hydrocarbons with more limited carbon chains that have congruity with the idea of petroleum derivatives.

Gas creation in oil treatment facilities is generally produced by the Fluid Catalytic Cracking (FCC) unit. This unit works by isolating the feed chain into more limited length. This guideline permits the utilization of various kinds of feed, gives that the feed has longer hydrocarbon chains than petroleum. The advancement of vegetable oil breaking innovation is upheld by the exhaustion of oil holds and the need to keep up with the security of energy supply from sustainable crude materials [9]. Reactant breaking enjoys a larger number of benefits than other fatty substance preparing techniques. To start with, it can deliver different items like gas, natural fluid item (OLP), water, and coke. Nonetheless, enormous atoms existing in vegetable oils can only with significant effort infiltrate profound into more modest 1-2 $\mathrm{nm}$ pores of the impetus and consequently breaking impact is restricted to the moderately little response locales at the impetus surface. Bigger pore's distance across inside the impetus is the best answer for the issue [10]. Coke development doesn't turn into an issue for uncatalyzed breaking measure. OLP contain oxygen compounds (aldehydes, ketones, and carboxylic acids) and hydrocarbons (typical paraffin, naphthenic, and olefin) that match the limit scopes of fuel, lamp oil, and diesel. Second, the response temperature is lower than that of pyrolysis, and huge atoms are separated into more modest mixtures by lack of hydration, dehydrogenation, deoxygenation, and decarboxylation. Third, reactant breaking offers a generally cheaper course to energy consumption [3].

Contrasted and transesterification, which changes fatty substances over to biodiesel (methyl or ethyl esters of unsaturated fats), breaking enjoys a few benefits, for example, its low handling cost, and energy utilization for division measure. Reactant breaking can create more fluctuated kinds of fuel like gas and lamp oil, among different items just as diesel fuel. Notwithstanding, breaking measure typically needs high preparing temperature, and it becomes significant thought on its cycle wellbeing. In addition, higher energy utilization is likewise needed to support its exceptionally endothermic reaction [8].

Impetus expansion enjoys two primary benefits both to expand the pace of response and effectively specific toward specific items [2]. A few investigations have announced that the temperature needed for reactant breaking $\left(450^{\circ} \mathrm{C}\right)$ was normally lower than that of pyrolysis $\left(500-850^{\circ} \mathrm{C}\right)$ [3]. A scope of studies have examined the synergist breaking of palm oil utilizing diverse impetus at $450^{\circ} \mathrm{C}$ and $1-5 \mathrm{~atm}$ in research facility scale reactors. The subsequent items have looked like gas, lamp oil, and diesel fuel, with the predominant yield of gas [3]. Past examination has showed that ZSM-5 impetus advances the arrangement of fragrant and aliphatic hydrocarbons through deoxygenation measure corrosive division. The measure of sweet-smelling compounds in fluid items expanded within the sight of ZSM-5 impetus. The fragrant compound enjoys a benefit in expanding the octane number of fuel despite the fact that it ought to be restricted because of natural guideline [11].

\section{Materials and Methods}

\section{Waste Cooking Oil}

Squander cooking oil was gathered from close by food slows down. Squander cooking oil then, at that point sifted through a coarse sifter to eliminate its strong substance. Filtration measure is directed twice to guarantee no strong contained. Then, at that point squander cooking oil is put away at holder at room temperature and the structure was resolved utilizing Gas-Solid Chromathography.

\section{Catalyst Preparation}

Impetus ZSM-5 which got from Wish Chemicals Yueyang Factory, China in powder structure should be made in granular structure to work with the cycle of calcination and breaking. Granulation was done physically by adding the glue specialist as kaolin ( $5 \mathrm{wt} . \%$ ) to frame pellets of a similar size $0.3 \times 0.5 \mathrm{~cm}$. Moreover, impetus was enacted in the heater with a warming temperature of $450^{\circ} \mathrm{C}$ and followed by calcination by streaming nitrogen gas for 30 minutes. In the wake of being enacted and calcinated, the impetus was cooled and its trademark was dissected.

\section{Thermal Cracking}

$40 \mathrm{~mL}$ squander cooking oil was taken utilizing estimating chambers. Prior to being taken from its holder, squander cooking oil was shaken to guarantee that it is very 


\section{Petroleum \& Petrochemical Engineering Journal}

much blended. Both preheaters 1 and 2 were set in $430^{\circ} \mathrm{C}$ then the reactor was set in 450,500 , and $550^{\circ} \mathrm{C}$ for each running meeting. The preheater and reactor were likewise outfitted with a temperature control gadget to guarantee that the temperature stayed steady. The result of breaking measure was cooled in 3 phase's twofold line condenser which expects to change gas into natural fluid item.

\section{Catalytic Cracking Reaction}

The experiments were carried out in the temperature range of $450-550^{\circ} \mathrm{C}$ in a stainless steel tubular reactor $11 \mathrm{~cm}$ internal diameter) filled with catalysts with the length of 1 $\mathrm{cm}$ and equipped with 2 stages preheater to ensure that the oil enters the reactor in the vapor phase. The reactor and preheaters were also equipped with a temperature control device to ensure the temperature remained constant. The overall process was conducted in semi-batch operation mode. The oil flow rate was about $2 \mathrm{ml} /$ minute. For the first 20 minutes, waste cooking oil was supplied to the preheater gradually. Then, the system was maintained with gasses flow to the condenser continuously for about 2 hours. White colored vapor which contain several types of hydrocarbon were tend to condenses when it reached the end of the condenser as organic liquid product (Figure 1).

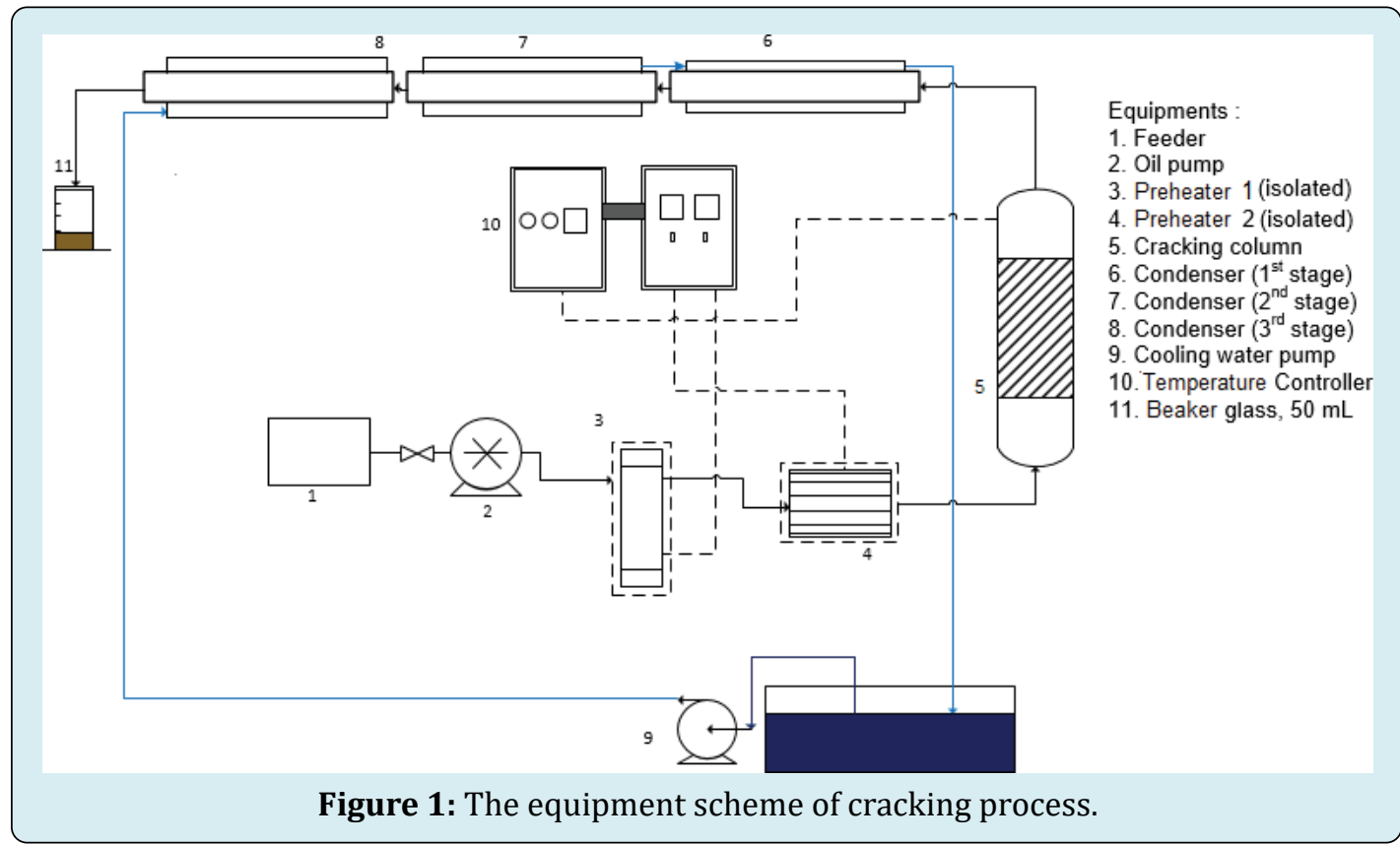

\section{Product Analysis}

The cracking product consists of organic liquid product (OLP), water, gas, and coke. The organic liquid product contains a large number of components of liquid hydrocarbons [11]. The OLP was analyzed using GC and GC-MS and grouped into 3 categories based on the number of atom carbon: $\mathrm{C}_{5}-\mathrm{C}_{11}, \mathrm{C}_{12}-\mathrm{C}_{15}$, and $\mathrm{C}_{16}-\mathrm{C}_{20}$ that then was arranged into categories based on the organic compounds such as paraffin, olefin, aromatic, cyclo-paraffin, acid, and alcohol. Because of the complexity of the product resulting from cracking processes, to calculate the selectivity of a particular product is using the percentage of each peak area to the total peak area of the compound obtained from the chromatogram [12]. The equipment used on this analysis was GC-MS QP2010S SHIMADZU with AGILENT HP1MS Column, and Helium as the gas carrier.

\section{Results and Discussion}

\section{The Effect of Temperature and ZSM-5 Catalyst to Products Yield}

The raw material used in this research is waste cooking oil that contains long chain carboxylic acid components comprise 10-octadecenoic acid, hexadecanoic acid, 9,12-hexadecadienoic acid, and several other fatty acids. Its density was $0.8974 \mathrm{gm} / \mathrm{mL}$. Generally, waste cooking oil has higher heating value than palm oil because of heating effect when it used for frying. Even though, the heating value of waste cooking oil resulted from calorimeter bomb test was $10,002.986 \mathrm{cal} / \mathrm{gr}$. But it does not mean that waste cooking oil can be used directly as a fuel. Its boiling point has to be lowered by cracking process, so becomes lighter fraction as combustion reaction takes place mainly at vapor phase [8]. 


\section{Petroleum \& Petrochemical Engineering Journal}

It is a clear connection that the interaction temperature becomes higher as the heap of cooling framework getting higher. Both warm and synergist breaking measure exhibitions have calculable diverse fluid items yields for various cycle temperatures. (Figure 2) uncovers that expanding temperature of breaking will in general diminish fluid item yield. This is because of the need of cooling framework load getting higher to arrive at the item's dew point temperature.

The development of non-condensable gases influences the fluid item yield. Additionally, in every result of warm breaking, there were roughly 5-15\% water which delivered and for synergist breaking 5-10\%. The presence of water, different oxygenated mixtures and acids lessens the dependability just as fuel quality. It is notable that the development of water is a result of biomass pyrolysis. Normally, water is produced because of the drying out response which happens at the underlying phase of biomass pyrolysis. This likewise relies upon the underlying dampness content and the oxygen content of the biomass feed [13]. Carbonylation response and hydrogen oxidation likewise occurred as an outcome of not totally anaerob measure. The consequence of warm and synergist breaking at different temperatures is recorded in (Table 1 ).

\begin{tabular}{|c|c|c|c|}
\hline Cracking Process & Temperature $\left({ }^{\circ} \mathbf{C}\right)$ & Residue (gram) & Product (mL) \\
& 450 & 22.2 & 8.25 \\
Thermal & 500 & 21.8 & 6.85 \\
& 550 & 19.61 & 6.9 \\
Catalytic & 450 & 15.17 & 4.95 \\
\hline
\end{tabular}

Table 1: Product of thermal and catalytic cracking processes.

Table 1 shows that the higher process temperature, the lower liquid product yield. Non-condensable gases such as methane, ethane, etc were mainly formed when high temperature process resulted in lower liquid product recovery. Figure 2 shows a relationship between liquid product recovery and process temperature for both thermal and catalytic cracking processes.

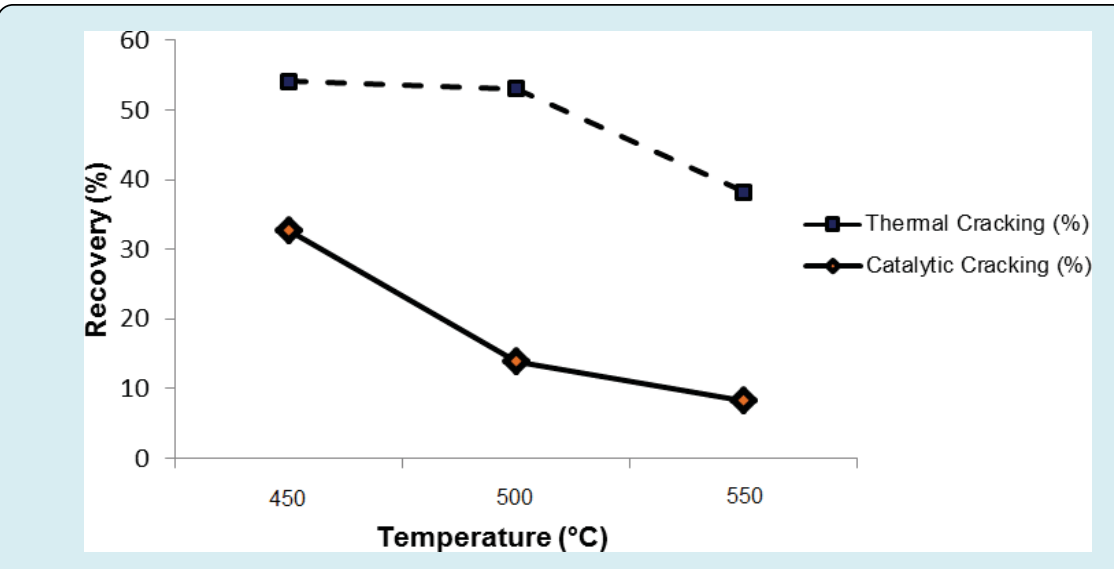

Figure 2: The relationship between recovery and cracking temperature.

\section{The Effect of Both Catalyst and Temperature to Organic Liquid Product (OLP) Caloric Value}

Caloric value is the energy content of a material per mass that is exhausted when the fuel is completely burned. Calorimeter bomb has been used by many researchers to analyze material caloric values for various applications. Caloric value becomes important property for a material which directly related to further usage as a type of fuel [14]. The heating value of several products and commercial fuels listed in (Table 2). 


\section{Petroleum \& Petrochemical Engineering Journal}

\begin{tabular}{|c|c|c|}
\hline No. & Fuels & Heatingvalue, cal/g \\
\hline 1 & Premium & 10509 \\
\hline 2 & Pertamax & 10575 \\
\hline 3 & Pertamax plus & 10622 \\
\hline 4 & Biosolar & 10546 \\
\hline 5 & Solar dex & 10755 \\
\hline 6 & Waste cooking oil & 10002.99 \\
\hline 7 & Therm $450^{\circ} \mathrm{C}$ & 10582.33 \\
\hline 8 & Therm $500^{\circ} \mathrm{C}$ & 10623.74 \\
\hline 9 & Therm $550^{\circ} \mathrm{C}$ & 10342.64 \\
\hline 10 & Catal $450^{\circ} \mathrm{C}$ & 10880.48 \\
\hline 11 & Catal $500^{\circ} \mathrm{C}$ & 10760.62 \\
\hline
\end{tabular}

Table 2: Heating value of several fuels.

Caloric value of products from catalytic and thermal cracking processes shows their characteristic. The product of catalytic cracking process tends to have higher heating value than the product of thermal cracking because the addition of catalyst in cracking process produce aromatic compounds which have high octane number. High octane number of compounds tends to support combustion reaction, prevent knocking which result in higher heating value [14]. Table 2 reveals that the heating value of cracking products tend to increase in the product of lower process temperature except its decreasing from $500^{\circ} \mathrm{C}$ to $450^{\circ} \mathrm{C}$ in thermal cracking processes. The caloric value of thermal and cracking products are appreciably similar to standard fuels marketed in Indonesia. The highest caloric value was exist at temperature of $450^{\circ} \mathrm{C}$ from catalytic process and the lowest caloric value at $550^{\circ} \mathrm{C}$ from cracking process without catalyst.

\section{The Effect of Catalyst on Type of Product Compounds}

The organic liquid products derived from thermal and catalytic cracking were analyzed using GC-MS and the results are shown in Table 3. It can be observed from this table that the liquid product is composed of various groups of organic compounds such as paraffin, olefins, aromatic, cyclic compounds, alcohol and carboxylic acid which are generally classified as bio-gasoline $\left(\mathrm{C}_{5}-\mathrm{C}_{11}\right)$, bio-kerosene $\left(\mathrm{C}_{12}-\mathrm{C}_{15}\right)$, and biodiesel $\left(\mathrm{C}_{16}-\mathrm{C}_{20}\right)$ depending on the lump of carbon atoms. From the result of GC-MS analysis showed that there is an increase in the group of $\mathrm{C}_{5}-\mathrm{C}_{11}$ in the catalytic cracking due to the secondary reaction is more dominant, so the liquid products consist of hydrocarbon compound with shorter carbon chain.

With catalyst, the oxygenated compounds which come from thermal cracking diffuse into the pores of catalysts and reacts with protons in the active site through several reaction pathways include dehydration, decarboxylation, decarbonylation, and oligomerization [11].

\begin{tabular}{|c|c|c|c|}
\hline \multirow{3}{*}{ Carbon Number } & \multirow{2}{*}{ Type of Hydrocarbon Compounds } & \multicolumn{2}{|c|}{ \% Distribution } \\
\cline { 2 - 4 } & & Catalytic Cracking & Thermal Cracking \\
\hline \multirow{4}{*}{ C5-C11 } & Paraffin & 20.12 & 38.61 \\
\cline { 2 - 4 } & Olefins & 11.51 & 32.41 \\
\cline { 2 - 4 } & Cyclic & 1.02 & 3.11 \\
\cline { 2 - 4 } & Aromatic & 34.6 & 0 \\
\hline \multirow{4}{*}{ C12-C15 } & Alcohol & 0.56 & 14.89 \\
\cline { 2 - 4 } & Paraffin & 22.01 & 7.46 \\
\cline { 2 - 4 } & Olefins & 3.78 & 0 \\
\cline { 2 - 4 } & Cyclic & 0.56 & 0 \\
\hline & Aromatic & 0 & 0.91 \\
\cline { 2 - 4 } & Alcohol & 0 & 2.61 \\
\cline { 2 - 4 } & Paraffin & 3.94 & 0 \\
\cline { 2 - 4 } & Olefins & 0.35 & 0 \\
\cline { 2 - 4 } & Cyclic & 0 & 0 \\
\hline
\end{tabular}

Table 3: Distribution of hydrocarbons compounds in the liquid products of waste cooking oil cracking based on the number of carbon atoms observed from GCMS analysis. 


\section{Petroleum \& Petrochemical Engineering Journal}

The result shows that the ZSM-5 catalyst promotes the formation of aromatic hydrocarbons through deoxygenated process of acid fraction. The amount of aromatic compound increase in the presence of ZSM-5 catalyst from 0 to $34.60 \%$. The increasing number of aromatic compounds shows that the ZSM- 5 facilitates the reaction of aromatization. Besides, olefin content of the product decreases in the presence of ZSM-5 catalyst from 32.41 to $11.51 \%$ for bio-gasoline fraction and from 7.46 to $3.78 \%$ for bio-kerosene fraction. With the use of catalyst, paraffin content of the product decreases from 38.61 to $20.12 \%$ for bio-gasoline fraction and increases from 14.89 to $22.01 \%$ for bio-kerosene fraction.

The relationship between \% distribution and lump of hydrocarbon compounds is shown in Figure 3. Overall $\left(\mathrm{C}_{16}-\mathrm{C}_{20}\right)$ content of both cracking products is below $6 \%$. Biokerosene contents are increase as ZSM- 5 catalyst introduced to the process. Overall, the products contain $74.13 \%$ biogasoline for thermal cracking process, and $67.81 \%$ for catalytic cracking process. Thus, bio-gasoline content from thermal cracking process is higher than catalytic cracking process.

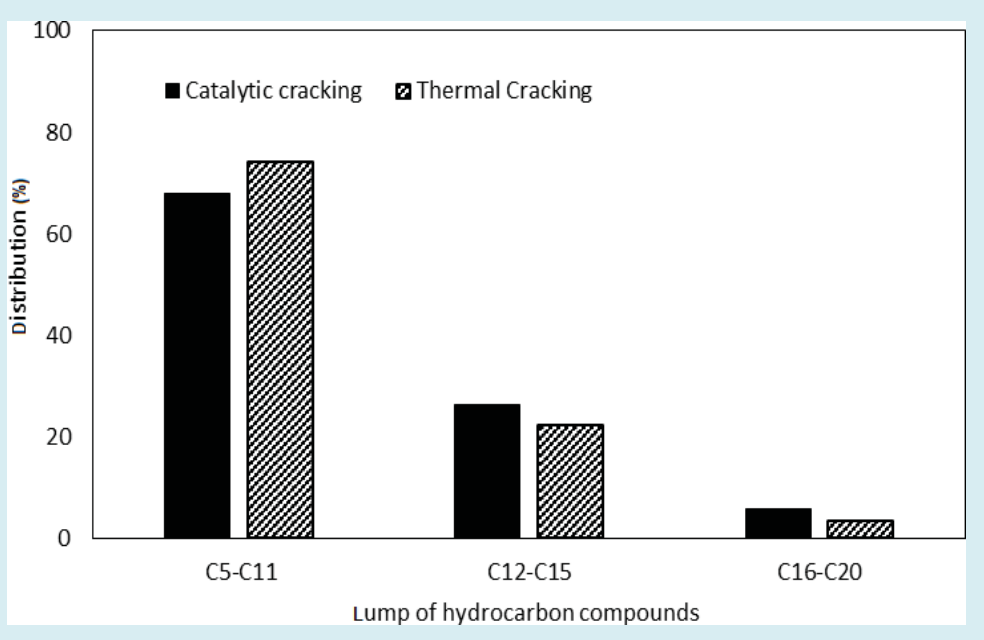

Figure 3: The relationship between \% distribution and lump of hydrocarbon compounds.

\section{Conclusions}

In this investigation, both warm and synergist breaking measures were directed to change over squander cooking oil into bio-fuel. A few boundaries may influence measure execution which brought about various item's yield and determination. Breaking temperature variety gave calculable impact on yield and item's caloric qualities. Higher breaking temperature supported non-condensable gases arrangement so that bio-gas got becomes lower and brought about higher cooling burden to accomplish gas' dew point temperature. The rate recuperation of natural fluid item from the breaking interaction changes from the most reduced yield of $8.31 \%$ to the ideal yield of $54.08 \%$. Warming up sides of bio-fuels was different in view of the diverse breaking temperature and presented impetus. The most noteworthy caloric substance accomplished by the result of reactant breaking at $450^{\circ} \mathrm{C}$ with its caloric worth of $10,880.48 \mathrm{cal} / \mathrm{g}$, becomes tantamount with a few standard fills. Synergist movement of ZSM-5 showed that the impetus worked on the selectivity of hydrocarbon compounds by diminishing the bothersome oxygenated compounds and advanced the development of sweet-smelling and aliphatic hydrocarbons. Reactant breaking measure with ZSM-5 impetus brings about lower bio-gas content.

\section{References}

1. Emori EY, Hirashima FH, Zandonai CH, Ortiz-Bravo CA, Machado NRCF, et al. (2016) Catal Today 10281: 1-9.

2. Istadi (2011) Teknologi Katalisuntuk Konversi Energi: Fundamental dan Aplikasi. Katalisis Reaksi kimia, pp: 13-124.

3. Mancio AA, da Costa KMB, Ferreira CC, Santos MC, Lhamas DELS, et al. (2012) Thermal catalytic cracking of crude palm oil at pilot scale: Effect of the percentage of $\mathrm{Na}_{2} \mathrm{CO}_{3}$ on the quality of biofuels. Ind Crops Prod 91: $32-43$.

4. Melero JA, Iglesias J, Garcia A (2012) Biomass as renewable feedstock in standard refinery units. Feasibility, opportunities and challenges. Energy Environ Sci 5: 7393-7419.

5. Kementerian Pertanian (2015) Rencana Strategis Kementrian Pertanian Tahun (2015-2019). 


\section{Petroleum \& Petrochemical Engineering Journal}

6. Gopal KN, Pal A, Sharma S, Samanchi C, Sathyanarayanan $\mathrm{K}$, et al. (2014) Investigation of emissions and combustion characteristics of a CI engine fueled with waste cooking oil methyl ester and diesel blends. Alexandria Engineering Journal 53(2): 281-287.

7. Kawentar WA, Budiman A (2013) Synthesis of Biodiesel from Second-Used Cooking Oil. Energy Procedia 32: 190199.

8. Mouljin JA, Makkee M, Van Diepen AE (2013) Chemical Process Technology. $2^{\text {nd }}$ (Edn.), John Wiley \& Sons Ltd, NY, USA.

9. Savitri R, Effendi G, Primahana S, Tursiloadi (2015) Cracking Callophyllum Innophyllum L. Oil to Bio-gasoline by Micro-porous Based Zeolite and Al203 Catalysts. Procedia chem 16: 555-562.

10. Abbasov V, Mammadova T, Aliyeva N, Abbasov M, Movsumov N, et al. (2016) Catalytic cracking of vegetable oils and vacuum gasoil with commercial high alumina zeolite and halloysite nanotubes for biofuel production.
Fuel 181: 55-63.

11. Dewajani H, Rochmadi, Purwono S, Budiman A (2016) Effect of modification ZSM-5 catalyst in upgrading quality of organic liquid product derived from catalytic cracking of Indonesian nyamplung oil (Calophylluminophyllum). $1^{\text {st }}$ International Conference on Science and Technology, AIP Conference Proceedings, American Institute of Physics, 1755(1): 1- 5.

12. Dewajani H, Rochmadi, Purwono S, Budiman A (2016) Kinetic Study of Catalytic Cracking of Indonesian Nyamplung Oils (Calophyllum Inophyllum) Over Zsm-5 Catalyst. ARPN JEAS 11(8): 5221-5226.

13. Koul M, Shadangi KP, Mohanty K (2016) J Anal Appl Pyrol 3713: 1-7.

14. Irzon R (2012) Perbandingan Calorific Value Beragam Bahan Bakar Minyak Yang Dipasarkan Di Indonesia Menggunakan Bomb Calorimeter. Jurnal Sumber Daya Geologi 22(4): 217-223. 